\title{
Professional ecological knowledge: an unrecognized knowledge domain within natural resource management
}

\author{
Forrest Fleischman $^{1}$ and David D. Briske ${ }^{1}$
}

\begin{abstract}
Successful natural resource management is dependent on effective knowledge exchange and utilization. Local/traditional/ indigenous knowledge derived from place-based experience and scientific knowledge generated by systematic inquiry are the most commonly recognized knowledge domains. However, we propose that many natural resource decisions are not based on local or scientific knowledge, but rather on a little recognized domain that we term professional ecological knowledge (PEK). Professional ecological knowledge is founded upon codification of broad ecological principles, but not necessarily scientific evidence, to legitimize agency programs, support operational efficiency, and encourage user compliance. However, in spite of these benefits, PEK may reduce program effectiveness by inhibiting the exchange of local and scientific knowledge and minimizing the development of evidence-based conservation. We describe what we consider to be common facets of PEK through case studies examining the sources of knowledge utilized by forestry agencies in India and by rangeland conservation programs of the USDA Natural Resource Conservation Service. Three propositions are presented regarding the origins and continued existence of PEK: (1) minimal information feedbacks regarding the efficacy of agency programs contributes to development of PEK; (2) a narrow scientific agenda and a perception that most scientific knowledge is not relevant to management decisions encourages a divide between scientists and managers; and (3) political interests often benefit from existing applications of PEK. By calling attention to the existence of PEK as a distinctive knowledge domain, we aim to encourage more explicit and critical consideration of the origins of knowledge used in environmental decision making. Explicit recognition of PEK may provide greater understanding of the dynamics of knowledge exchange and decision making in natural resource management.
\end{abstract}

Key Words: government agencies; knowledge domains; knowledge integration; local knowledge; scientific knowledge; science-policy gap

\section{INTRODUCTION}

Successful natural resource management is dependent on effective knowledge exchange and utilization (Holling and Meffe 1996, Roux et al. 2006, Fazey et al. 2013). Although there has been substantial research devoted to comparing the knowledge of natural resource users with that of scientists (Berkes 1999, Davis and Ruddle 2010, Raymond et al. 2010), less attention has been devoted to examining the knowledge used by government natural resource managers. Agency professionals typically have substantial training in a natural science discipline related to the mission of their agency, for example, most employees of forestry agencies in the U.S. have bachelors or master's degrees in forestry or other relevant natural resource management disciplines, such as range management or wildlife biology (Kaufman 1960, Tipple and Wellman 1991, Koontz 2007). However, their primary responsibilities are not to engage in research or scholarship, but to implement programs designed by their respective agencies. Even though these professionals may live near the natural resources they manage, the bureaucratic nature of their work and authority of their positions often separates them from rural livelihoods and direct observation of management outcomes. Consequently, opportunities for systematic or long-term observation may be limited (Roux et al. 2006, Fleischman 2015).

The knowledge used by professional resource managers, particularly those in public agencies, is important because these managers play an important role in decision making about public and private land use around the world. For example, approximately $75 \%$ of the world's forests are formally owned by governments (Agrawal et al. 2008, Sunderlin et al. 2008), and much of the remainder is subject to regulatory oversight (McDermott et al. 2010, McGinley et al. 2012). Similarly, many rangelands in the U.S. are publicly owned and managed by government agencies, whereas those that are in private ownership often enroll in voluntary cost-share programs offered by the Natural Resource Conservation Service (NRCS) to pursue conservation objectives (Briske 2011). Although government agencies are rarely the sole actors influencing natural resource management decisions, they usually play an important role.

We posit that government agencies responsible for natural resource management often rely on neither local nor scientific knowledge, but that they develop and implement a distinct type of knowledge, which we term professional ecological knowledge (PEK), to conduct their missions and implement programs. We review the existing literature regarding the knowledge developed and implemented by professional managers in government agencies and show that it is both limited and inconsistent in its interpretation relative to that of local and scientific knowledge. We then use case studies of two very different government natural resource agencies to demonstrate the existence of PEK and to assess its potential consequences. These case studies are of forest departments in India, which are the legal owners and managers of the vast majority of India's forest land, and the NRCS in the U.S. Department of Agriculture, which is primarily responsible for administering technical assistance and cost-share programs for private land owners across the U.S. Finally, we discuss the broad implications of PEK on knowledge exchange and decision making in natural resource management. 


\section{Forms of ecological knowledge}

We define knowledge as a combination of experiences, values, contextual information, and intuition, which provides a framework to evaluate and incorporate new experiences and information (Roux et al. 2006). A wide variety of categorizations of knowledge exist within the natural resource management literature, and controversy exists regarding the value of these knowledge domains (Agrawal 1995). However some common ground can be found in the perception that knowledge is arrayed along a continuum bounded by scientific and local knowledge (Davis and Ruddle 2010, Raymond et al. 2010). Scientific knowledge is derived from organized, systematic inquiry and aims for generalizable objectivity, explicitness, abstraction, mechanistic description, and transferability across contexts (Agrawal 1995, Roux et al. 2006). Local, traditional, and indigenous knowledge are developed through resource users' experiences and informal observations of resources, and tend to be subjective, holistic, place based, problem oriented, but highly implicit thus complicating attempts to define, encode, and transfer this knowledge (Raymond et al. 2010). Traditional and indigenous ecological knowledge are further characterized by their cultural embeddedness and transfer across generations (Olsson and Folke 2001). We follow Raymond et al. (2010) and broadly use local knowledge to describe knowledge developed and applied by various natural resource users, including those who possess and do not possess traditional or indigenous knowledge, to derive their livelihoods.

The existing literature contains conflicting accounts of how the knowledge of government agencies fits into these knowledge domains. Some authors treat government officials as holders of scientific knowledge. For example, Gadgil and Berkes (1991) contrast indigenous resource management systems with those developed by modern governments based on ecology, whereas Scott (1998) sees the development of scientific forestry in the 19th century as fundamentally tied to the creation of government regulation. By contrast, in seeking to integrate local and scientific knowledge, Raymond et al. (2010) interviewed a number of stakeholders whom they considered to hold local knowledge, including government bureaucrats.

These inconsistencies partially originate from the difficulty of distinguishing among domains arrayed along a knowledge continuum. In a survey of over 1000 Australian protected area practitioners, Cook et al. (2009) found that $90 \%$ of the practitioners' decisions relied largely on experience-based knowledge and were made without evidence-based knowledge. A survey of conservation managers in the UK by Pullin et al. (2004:245) reported: "the majority of conservation actions remain experience-based and rely heavily on traditional land management practices." Cook et al. (2009) considered their study to represent an evaluation of the local knowledge of practitioners, but it is not clear if their respondents had in fact lived or worked in the same ecosystem for sufficient time to develop local knowledge. Similarly, Pullin et al. (2004) referred to traditional land management, but they did not define traditional, so it is not clear if it refers to long-established practices representing what Olsson and Folke (2001) would call local knowledge, or merely to the status quo of current practices. All three groups of investigators assumed that if knowledge is not scientific, it must be local, but none explicitly investigated the origin of nonscientific knowledge.
Edelenbos et al. (2011) argued that government officials are the primary holders of an additional knowledge domain that they term bureaucratic or administrative knowledge. It specifically refers to the knowledge of government procedures, as opposed to knowledge of natural resource management in ecological systems. They claim it "is also based on professional and scientific grounds, but it has less strict checks and balances compared to scientific peer review" (Edelenbos et al. 2011:676). Because the focus of their work was on the coproduction of knowledge in Dutch water management systems, they did not provide a detailed description of the specific bureaucratic knowledge that was used, nor how it differed from other knowledge domains. It is certainly conceivable that hybrid knowledge may be developed through the combination of two or more knowledge domains (Raymond et al. 2010).

\section{Professional ecological knowledge}

In contrast to the knowledge domains described, we argue that PEK is founded upon codification of broad ecological principles, but not necessarily scientific evidence, to inform and legitimize standard agency programs and protocols, to support uniform implementation, and to encourage user compliance. We argue that PEK differs from local knowledge because it is not grounded in direct experience of natural resources to support human livelihoods, and that it differs from scientific knowledge because it is not directly derived from systematic inquiry. Therefore, we consider PEK to be a unique knowledge source, rather than a form of hybrid knowledge. Furthermore, it differs from bureaucratic/administrative knowledge as described by Edelenbos et al. (2011) in that it is knowledge about natural resource use and management, as opposed to knowledge merely of administrative procedures. Common examples of codification of PEK include best management practices, procedural manuals, and technical guides that often come to be thought of as verified scientific knowledge by personnel who use them. Codification of PEK is often shaped by legal or regulatory considerations that specify prescribed actions regardless of their scientific legitimacy or fit to local natural resources conditions. For example, Arnold and Fleischman (2013) described how court decisions in the U.S. forced wetlands regulators to use a regulatory standard that is ecologically meaningless.

We suggest that PEK may possess fewer and less direct information feedbacks to evaluate, self-correct, and create new knowledge than do local and scientific knowledge domains (Table 1). For example, decisions based on local knowledge are vetted through direct outcomes influencing human livelihoods, whereas scientific knowledge is vetted through hypothesis testing and peer review. Professional ecological knowledge is often vetted upon the rate and effectiveness with which standardized programs and protocols have been followed, implemented, and completed. In these circumstances, monitoring often emphasizes program implementation and compliance, rather than natural resource outcomes originating from these programs (Ferraro and Pattanayak 2006, Batie 2009). Minimal information feedbacks from the implementation of agency programs and policies serve to promote the development of PEK by isolating it from the natural resources being managed, as well as from associated local and scientific knowledge domains (Holling and Meffe 1996, Ludwig 2001). The conditions that give rise to PEK are likely to vary among agencies, or within divisions of the same agency, such 
Table 1. Comparing forms of knowledge.

\begin{tabular}{|c|c|c|c|c|}
\hline & $\begin{array}{l}\text { Scientific } \\
\text { knowledge }\end{array}$ & $\begin{array}{l}\text { Local/traditional/indigenous } \\
\text { ecological knowledge }^{\dagger}\end{array}$ & $\begin{array}{l}\text { Administrative/ } \\
\text { bureaucratic knowledge }\end{array}$ & $\begin{array}{l}\text { Professional ecological } \\
\text { knowledge }\end{array}$ \\
\hline $\begin{array}{l}\text { Possessors of } \\
\text { knowledge }\end{array}$ & $\begin{array}{l}\text { Scientists, educators, tech. } \\
\text { specialists }\end{array}$ & $\begin{array}{l}\text { Local resource users, managers, } \\
\text { service providers }\end{array}$ & Government officials & $\begin{array}{l}\text { Agency professionals at } \\
\text { multiple levels }\end{array}$ \\
\hline $\begin{array}{l}\text { Origin of } \\
\text { knowledge }\end{array}$ & Systematic inquiry & $\begin{array}{l}\text { Experience with resource, cultural } \\
\text { tradition }\end{array}$ & $\begin{array}{l}\text { Administrative procedure and } \\
\text { actions }\end{array}$ & $\begin{array}{l}\text { Agency mission, regulation, } \\
\text { tech. guides }\end{array}$ \\
\hline $\begin{array}{l}\text { Knowledge } \\
\text { content }\end{array}$ & $\begin{array}{l}\text { Ecosystem variables, } \\
\text { parameters, and responses }\end{array}$ & $\begin{array}{l}\text { Ecosystem capacity to support } \\
\text { livelihoods }\end{array}$ & $\begin{array}{l}\text { Decision making for public } \\
\text { interest }\end{array}$ & $\begin{array}{l}\text { Best management practices, } \\
\text { resource use regulations }\end{array}$ \\
\hline $\begin{array}{l}\text { Sources of } \\
\text { feedback }\end{array}$ & $\begin{array}{l}\text { Hypothesis testing, peer- } \\
\text { review, public critique }\end{array}$ & $\begin{array}{l}\text { Observation, human well-being, } \\
\text { cultural persistence }\end{array}$ & $\begin{array}{l}\text { Legal proceedings, public } \\
\text { hearings }\end{array}$ & $\begin{array}{l}\text { Legal proceedings, public } \\
\text { critique }\end{array}$ \\
\hline
\end{tabular}

that some will rely primarily on PEK, but others may effectively incorporate scientific or local knowledge into their decision making (Desmarais and Hird 2014). These conditions may provide useful entry points to further investigate the development and implications of PEK.

\section{CASE STUDIES OF KNOWLEDGE USE IN NATURAL RESOURCE MANAGEMENT}

We present two case studies of knowledge application in two very different natural resource agencies, forest departments in India and rangeland conservation in the U.S. NRCS, to further demonstrate the occurrence of PEK and to identify its potential implications. By providing two cases of PEK, we demonstrate the existence of the phenomenon we have described (Campbell 1975, George and Bennett 2005). In addition, we use these as heuristic cases to develop greater insight into the knowledge domains used by government agencies to manage natural resources (George and Bennett 2005).

\section{Planting trees in Central India}

Our first case study of agency knowledge comes from forests in India. India has a long tradition of government forestry dating back to the mid-19th century, and early in the 20th century it was seen as a global leader in forest science (Saberwal 1999, Barton 2002). The primary objective of Indian forestry at this time was timber production to meet industrial demands, and forest science emphasized the maximum sustainable yield model to support this objective. This model introduces management practices to maintain system stability so the yield of one or a few products can be optimized, timber production in this particular case (Holling and Meffe 1996). Although subsequent policy revisions now place greater emphasis on support for rural livelihoods and biodiversity conservation, and commercial uses have been greatly restricted (Ministry of Environment and Forests 1988), contemporary forestry practices continue to emphasize the traditional objective of timber production (Fleischman 2014, 2015). This is reflected in the knowledge base of many foresters, which emphasizes knowledge of commercial timber species over that of other forest products and ecosystem services (Robbins 2000).

Although Indian forest officials proudly describe the work they do as scientific forestry, foresters in India currently have little scientific knowledge available to guide their decision making. It is highly unusual for forest planning documents to contain citations to any form of scientific study or publication. Forestry training is conducted primarily in government-run forestry training institutes, which are staffed by senior field foresters, not academic researchers. Curriculum in these institutes is conservative, often passing down knowledge and management practices that date back 100 years (Hannam 2000) and draw primarily on the sustained yield models developed by 19 th century forest scientists (Stebbing 1922, Gadgil and Guha 1992, Barton 2002). The bias toward commercial activities is reflected in departmental research programs, which focus almost exclusively on improving techniques for commercial plantations, and which continue to draw on the sustained yield model (Fleischman 2014). Forest departments have a history of poor cooperation with independent scientists (Lewis 2002, 2004, 2005, Madhusudan et al. 2006), and ecological knowledge in India remains limited (Singh and Bagchi 2013). Thus, although the knowledge of foresters may have some basis in scientific theories, most practices of forest officials are likely to have a very limited grounding in scientific knowledge simply because scientific knowledge is highly limited, and there is little knowledge exchange between scientists and managers.

At the same time, most foresters have few opportunities to develop local knowledge. It is not clear how many forest officials come from social backgrounds with extensive knowledge of forests. Robbins (2000) reported that a small percentage of lower-ranked agency personnel shared knowledge with local forest users because of their backgrounds, but Hannam (2000) and Fleischman (2014) indicated that higher-ranking officials rarely come from backgrounds in which they had significant knowledge of forestry. Robbins reported that most foresters preferred fastgrowing, commercially valuable exotic species; a preference they shared with well-off and high caste members of surrounding communities who profited from timber production, implying that their knowledge was a product of regional political-economic preferences. Once on the job, forest officers are transferred every two to three years to minimize development of corrupt local ties (de Zwart 1994, Iyer and Mani 2012), so they rarely observe the long-term impact of their decisions and thus do not have opportunities to develop local knowledge. Professional foresters do interact with local villagers who possess extensive local knowledge, but the prevailing power imbalances make villagers reluctant to criticize forest officials, and forest officials do not consider villagers a reliable knowledge source (Fleischman 2014). 
What knowledge guides decision making if it's not scientific or local knowledge? According to Fleischman (2014), much knowledge derives from management prescriptions developed by upper-level officials and other senior policy makers, who themselves base their knowledge on elements taught in forestry training institutes, the same institutes that Hannam (2000) reported using 100 year-old textbooks. These training institutes have continued to focus on the maximum sustained yield model. Resulting management prescriptions, which reinforce the knowledge of officials, are developed based on older ecological principles, with modifications to suit contemporary conditions. For example, Fleischman (2014) reported that because of low stocking rates, many management plans now focus on creating intensive plantations rather than on planning harvest schedules, yet sustained yield models underlie both types of management plans, to the exclusion of consideration of broader ecological characteristics such as biodiversity or ecosystem function. Foresters come to believe that tree planting practices are valuable precisely because they are encoded in the mission and training programs of an agency, but in fact, those tree planting practices are not effective at achieving the contemporary objectives of protecting biodiversity or improving rural livelihoods. Instead, they are a relic of an older focus on timber production that is no longer the primary agency mission (Fleischman 2014). Management prescriptions for issues other than tree planting have not been studied systematically, but appear to be driven by the experience of foresters in the field, although given the lack of sustained contact with a single locale may mean that this is not genuinely local knowledge. Notably, although this knowledge may derive from management prescriptions, it is distinct from the bureaucratic/administrative knowledge described by Edelenbos et al. (2011), because this is knowledge about forest ecology and management, rather than knowledge of administrative processes, which officials also possess.

\section{Assessment of rangeland conservation in the U.S.}

The U.S. Department of Agriculture, Natural Resources Conservation Service (USDA-NRCS) is responsible for administering programs to promote conservation on private lands through various cost-share programs (Briske 2011). This agency initiated the Conservation Effects Assessment Project (CEAP) in 2003, in response to a call from the Office of Management and Budget for greater accountability of the societal benefits of federal conservation funding on 166 million hectares of privately owned rangelands in the U.S. A team of 40 scientists, interacting with 30 NRCS partners, was assembled to assess the effectiveness of 7 major rangeland conservation practices that had received the greatest funding and had been most widely implemented. The CEAP assessment team treated the stated goals and anticipated outcomes of the agencies' conservation practice standards, i.e., protocols that establish the priorities and procedures for these cost share programs, as hypotheses that were tested with relevant published experimental data. We consider these practice standards to represent explicit forms of PEK.

The assessment found little evidence of conservation benefits in the form of increased provision of ecosystem services or the reduction of natural resource degradation (Briske et al. 2011). However, this conclusion was primarily a consequence of minimal monitoring of the ecological outcomes of these conservation practices, rather than an assessment of the effectiveness of the conservation practices per se. The assumptions of predictability and control associated with the maximum sustainable yield model may have provided a self-reinforcing mechanism that minimized the perceived need for monitoring program outcomes because they were considered a certainty in this highly simplified model. This interpretation is consistent with the doctrine of truncation in which government agencies attempt to reduce the complexity of their missions through the use of programs and policies (Ascher 2001).

It was clearly evident that the current conservation practice standards had not kept pace with scientific advances that have occurred in the past two or three decades. A review of conservation practices standards every five years is mandated by the agency, but these are conducted within the agency with little or no external knowledge exchange. Conservation standards addressing contemporary natural resource issues, invasive plant management in particular, were poorly developed relative to the available scientific knowledge and the scope of the problem that they pose to rangeland systems (Briske 2011). Unlike the Indian forestry documents, citations were included in the 2010 conservation practice standards. We calculated the mean age of the 52 citations included in the 7 conservation practice standards to be 18 years, and only $10 \%$ of these were peer reviewed journal articles, with the majority evenly distributed between government reports and books. This is consistent with the findings of Desmarais and Hird (2014) indicating that the mean age of citations in USDA regulatory impact analyses was 17.3 years, the oldest of 13 federal agencies evaluated. This supports the contention that agency conservation practice standards are based on broad and often outdated ecological principles, rather than on contemporary scientific evidence. This further suggests that scientific knowledge is considered unimportant to the development of conservation practice standards or that insufficient capacity exists within the agency to manage its exchange and adoption. Given that the conservation standards were developed at the national level, with allowances for some regional modification within individual states, they also do not meet any reasonable definition of local ecological knowledge.

\section{DISCUSSION}

The two cases that we have reviewed suggest that a considerable body of knowledge within these agencies fits neither the definitions of scientific nor local knowledge as described in the literature. Neither the knowledge used by Indian foresters, which continues to emphasize production forestry in the form of tree planting, nor the knowledge used by NRCS administrators to develop conservation practice standards is based on experiences of natural resource users. Although derived in part from broad and often dated ecological theories, the knowledge in use is not scientific, in the sense of being critically vetted by experimental evidence or peer review. Finally, although this knowledge is shaped by administrative procedures within agencies (Edelenbos et al. 2011), it extends beyond agency operations to guide natural resource decision making.

\section{Creation of professional ecological knowledge (PEK)}

We propose that this body of knowledge created and implemented by these two agencies is best termed professional ecological knowledge (PEK). This knowledge domain is derived from professional training and experience and by application of 
standardized administrative protocols that are often codified versions of ecological principles whose applicability to particular sets of situations has not been tested scientifically. The development of PEK in both cases, even though they are on different continents and within different cultures, is suggestive of a common impetus for their creation. We contend that simplified models, primarily the maximum sustainable yield model, based on early 20th century ecological principles, which were codified into agency programs, may have provided this impetus. Once the influence of PEK on knowledge exchange and natural resource management decisions has been more clearly identified, it may prove to be a central component of what Holling and Meffe (1996:328) described as the "pathology of natural resource management," in which oversimplification and broad application of management strategies contributed to natural resource management failures (Acheson 2006). These case studies provide the basis for developing inferences about what drives the development of PEK. We posit that PEK may be more dominant in some agencies than others for systematic reasons. The three propositions below are meant to guide future research on the origin and consequences of PEK.

The first proposition is that PEK is more likely to develop when information feedback regarding the outcomes of agency programs are infrequent and limited. We posit that procedures that expose the knowledge of natural resource managers to criticism by other knowledge domains will limit the development of PEK. For example, managers who work for extended periods in a specific ecosystem are likely to have their knowledge tested by the observation of program outcomes and episodic events and thus benefit from or even develop local knowledge. By contrast, government employees who are rotated between postings in different regions, as Indian foresters are, are less likely to develop local knowledge. Furthermore, even if such local knowledge is developed by low-ranking field personnel (such as some of the forest guards discussed by Robbins 2000), this will have little meaning to the outcomes of agency programs if they are not consulted by decision makers who, in most resource management agencies, work primarily in regional or national centers far removed from the natural resources being managed. Procedures that expose agency planning to public criticism, such as the notice and comment procedures enshrined in the U.S. National Environmental Policy Act, may also serve to limit the development of PEK (Yackee 2006, Nie 2008, Auer et al. 2011). If this is the case, we would expect that agencies whose work is subjected to less public criticism, such as the NRCS and Indian forest departments, to incorporate less scientific and local knowledge than agencies such as the U.S. Environmental Protection Agency and USDA Forest Service, which engage in substantially more notice and comment procedures.

Our second proposition is that the narrow research agenda adopted by natural resource disciplines early last century is partially responsible for the development of PEK (Ascher 2001). Science emphasizes precision and repeatability, but it often lacks sufficient context for successful natural resource management and policy applications because these actions occur within complex adaptive systems characterized by economic, political, and cultural considerations (Ludwig 2001, Dilling and Lemos 2011). Scientists are often more adept at sharing explicit information to advance understanding, rather than in knowledge generation and sharing to promote problem solving (Roux et al. 2006). Therefore, many agency professionals may perceive that current scientific knowledge is not relevant to the management decisions for which they are responsible (Ludwig 2001, Pullin et al. 2004). Insufficient policy-relevant science may have helped to create a space for development of PEK. Agencies that have their own scientific staff or work more closely with independent scientists may be less likely to develop PEK. More broadly, building bridges between agencies, scientists, and holders of local knowledge may require the cultivation of boundary crossing networks or organizations (Guston 2001, Lidskog 2014), which could emerge as a crucial strategy for counteracting the adverse elements of PEK.

Our third proposition is that PEK is more likely to develop and be implemented when it benefits powerful political interests. Political leaders may prefer PEK for two very different reasons. The first reason is that PEK may insure a steady flow of benefits from agency activities to the politically powerful. The NRCS' conservation programs and India's forest management programs both bring substantial benefits to well-organized groups of stakeholders. Conservation programs administered by the NRCS allocate large amounts of federal funds to private landowners who have historically been well-organized to retain these programs in the federal budget (Olson 1965, Rowley 1985). Similarly, forest science that focuses on maximizing sustained yield maintains high levels of timber extraction, which is beneficial to the well-organized timber industries, which have historically dominated forest policy in both the U.S. and India (Gadgil and Guha 1992, 1995, Hirt 1994, Clarke and McCool 1996). Managers may perceive independent scientists as threats to their political authority and may react defensively to scientific information, or, when they have the power, they may actively exclude scientists from even conducting research, as has apparently been the case in Indian forest management (Lewis 2002, 2004, 2005, Madhusudan et al. 2006). If this were the case, we would expect PEK to be more limited in contexts in which political competition is robust and no single political interest dominates an agency's agenda.

The second reason that PEK may be favored by the politically powerful is that it simplifies the complex task of supervising program implementation. Agency supervisors in the executive, legislative, and/or judicial branches of government, as well as senior managers within agencies, go to great lengths to insure that personnel at various levels of the agency hierarchy perform their duties according to agency protocols. Modern governments are incapable of functioning without clear channels of supervision (Kaufman 1960, McCubbins et al. 1987, 1989, Wood and Waterman 1991, Miller 1993). Both scientific and local knowledge require constant adjustment to local conditions, which makes supervision more complicated. By contrast PEK insures that all agency activities are implemented in a similar way, making supervision more tractable, as is the case for tree planting in India, but at the risk of oversimplification of natural resource problems (Fleischman 2014). Uniform procedures may also aid in the building of a strong organizational identity as was apparently the case for both the Indian forest departments (Stebbing 1922, Saberwal 1999) and the U.S. Forest Service (Kaufman 1960, Carpenter 2001, Sayre 2010) in the early 20th century. If this were the case, we would expect that agencies with greater reliance on PEK would effectively make decisions that are consistent with 
agency protocols, even though they may be less appropriate to the local conditions.

\section{Opportunities and barriers for knowledge exchange}

Opportunities and mechanisms by which scientific and local knowledge can be incorporated into agency procedures to influence outcomes likely vary among agencies, and even among programs within an agency. We suggest above that public review, including by the scientific community, of agency procedures may encourage adoption of scientific or local knowledge and limit the development of PEK. The NRCS conducts confidential, internal reviews of conservation practice standards and delivers technical recommendations to individual landowners (Briske 2011), which is less likely to promote the exchange of either local or scientific knowledge compared to the public reviews of agency actions required in other U.S. environmental agencies. Similarly, administrative units of the U.S. Forest Service that have researchers actively working in them are more likely to incorporate contemporary scientific knowledge (Stankey et al. 2003, 2005).

The organizational structure and procedures of agencies often create barriers to the flow of scientific knowledge (Roux et al. 2006). Training programs that emphasize adherence to rigid agency procedures or rely on broadly defined and simplistic ecological principles may convince managers that they are technically trained, while failing to convey specific scientific information. Hannam (2000) found that Indian forestry training programs have exactly this effect. Even when managers have an interest in pursuing scientific information, they may lack access to peer-reviewed scientific literature (Pullin et al. 2004), and this results in frequent citation of government reports, popular sources, and outdated scientific information (Pullin et al. 2004, Desmarais and Hird 2014). Internal promotion procedures that reward loyalty or focus on achieving administratively defined targets, rather than creating successful natural resource outcomes, may also incentivize individuals not to recognize or question PEK (Weiss 1988, Teodoro 2011). Barriers to knowledge exchange, similar to those that may have contributed to development of PEK, may be partially responsible for the difficulty that government agencies are currently encountering with the development and implementation of climate change planning (Jantarasami et al. 2010, Archie et al. 2012). The major barriers identified for the development of climate change programs include unclear mandates and implementation procedures from upper administration, insufficient delegation of authority, and inadequate knowledge.

\section{CONCLUSIONS}

Researchers studying the knowledge used by government agencies often make one of two unsubstantiated assumptions. They assume that because natural resource managers are professionals with advanced degrees, they use scientific knowledge (Gadgil and Berkes 1991, Scott 1998), while others assume that because professional managers conduct their work in a specific locale, often for extended periods of time, they use local knowledge (Pullin et al. 2004, Cook et al. 2009, Raymond et al. 2010). However, government agencies responsible for natural resource management may often rely on neither scientific nor local knowledge, but on a distinct knowledge domain we term professional ecological knowledge (PEK). The existence of PEK may be both a symptom of and a barrier to knowledge exchange in government agencies and its recognition may provide an important insight into why many natural resource agencies possess a limited capacity for knowledge exchange (Roux et al. 2006). By calling attention to the existence of PEK as a distinctive knowledge domain, we aim to encourage more explicit and critical consideration regarding the origins of knowledge used in environmental decision making. Confusing PEK with scientific or local knowledge may lead managers to underinvest in scientific investigation or knowledge exchange with scientists and possessors of local knowledge, as appears to be happening in both of the cases we examined.

Our case material is insufficient to identify the causes of PEK, or to understand how it can be ameliorated, however we have identified three propositions about the origin of PEK that merit further consideration: PEK may be limited by systems that encourage information feedback, in the form of boundary crossing networks or organizations or requirements for public participation; its development may be related to historically narrow ecological research agendas; and it may persist because it serves the interests of political leaders. Several important questions remain regarding the context and implications of PEK. To what extent does development of PEK vary among natural resource management agencies and professions? Does the organizational structure or primary mission of an agency influence its development? And perhaps most importantly, to what extent has PEK established barriers to impede knowledge exchange among local and scientific domains and under what conditions may it promote knowledge exchange among domains? Further investigation of PEK within multiple agencies may strengthen our understanding of how knowledge is exchanged among domains and incorporated into decision-making processes in natural resource management.

\section{Responses to this article can be read online at: http://www.ecologyandsociety.org/issues/responses. $\mathrm{php} / 8274$}

\begin{abstract}
Acknowledgments:
Nathan Sayre, Steven Wolf, Ajay Singh, Mike Petriello, and Linda Joyce made constructive contributions to earlier versions of the manuscript. Financial support for FFs contribution to this manuscript was provided by the US National Science Foundation (Graduate Research Fellowship \# 2007054263) and Texas A\&M Agrilife Research.
\end{abstract}

\section{LITERATURE CITED}

Acheson, J. M. 2006. Institutional failure in resource management. Annual Review of Anthropology 35:117-134. http:// dx.doi.org/10.1146/annurev.anthro.35.081705.123238

Agrawal, A. 1995. Dismantling the divide between indigenous and scientific knowledge. Development and Change 26:413-439. http://dx.doi.org/10.1111/j.1467-7660.1995.tb00560.x

Agrawal, A., A. Chhatre, and R. Hardin. 2008. Changing governance of the world's forests. Science 320:1460-1462. http:// dx.doi.org/10.1126/science.1155369 
Archie, K. M., L. Dilling, J. B. Milford, and F. C. Pampel. 2012. Climate change and western public lands: a survey of U.S. federal land managers on the status of adaptation efforts. Ecology and Society 17(4):20. http://dx.doi.org/10.5751/ES-05187-170420

Arnold, G., and F. D. Fleischman. 2013. The influence of organizations and institutions on wetland policy stability: the Rapanos case. Policy Studies Journal 41:343-364. http://dx.doi. org/10.1111/psj.12020

Ascher, W. 2001. Coping with complexity and organizational interests in natural resource management. Ecosystems 4:742-757. http://dx.doi.org/10.1007/s10021-001-0043-y

Auer, M., K. Richards, D. Seesholtz, B. Fischer, C. Freitag, and J. Grice. 2011. The U.S. Forest Service and its responsibilities under the National Environmental Policy Act: a work design problem. Public Organization Review 11:135-153. http://dx.doi. org/10.1007/s11115-010-0115-6

Barton, G. A. 2002. Empire forestry and the origins of environmentalism. Cambridge University Press, Cambridge, UK.

Batie, S. S. 2009. Green payments and the US Farm Bill: information and policy challenges. Frontiers in Ecology and the Environment 7:380-388. http://dx.doi.org/10.1890/080004

Berkes, F. 1999. Sacred ecology: traditional ecological knowledge and resource management. Taylor and Francis, Philadelphia, USA.

Briske, D. D. 2011. Conservation benefits of rangeland practices assessment, recommendations, and knowledge gaps. U.S. Dept. of Agriculture, Natural Resources Conservation Service, Washington, D.C., USA. [online] URL: http://www.nrcs.usda.gov/wps/portal/ nrcs/detail/ma/home/?cid=stelprdb1045811

Briske, D. D., N. F. Sayre, L. Huntsinger, M. Fernandez-Gimenez, B. Budd, and J. D. Derner. 2011. Origin, persistence, and resolution of the rotational grazing debate: integrating human dimensions into rangeland research. Rangeland Ecology and Management 64:325-334. http://dx.doi.org/10.2111/rem-d-10-00084.1

Campbell, D. T. 1975. III. "Degrees of freedom" and the case study. Comparative Political Studies 8:178-191.

Carpenter, D. P. 2001. The forging of bureaucratic autonomy: reputations, networks, and policy innovation in executive agencies, 1862-1928. Princeton University Press, Princeton, New Jersey, USA.

Clarke, J. N., and D. C. McCool. 1996. Staking out the terrain: power and performance among natural resource agencies. State University of New York Press, Albany, New York, USA.

Cook, C. N., M. Hockings, and R. W. Carter. 2009. Conservation in the dark? The information used to support management decisions. Frontiers in Ecology and the Environment 8:181-186. http://dx.doi.org/10.1890/090020

Davis, A., and K. Ruddle. 2010. Constructing confidence: rational skepticism and systematic enquiry in local ecological knowledge research. Ecological Applications 20:880-894. http://dx.doi. org/10.1890/09-0422.1
Desmarais, B. A., and J. A. Hird. 2014. Public policy's bibliography: the use of research in US regulatory impact analyses. Regulation and Governance 8:497-510. http://dx.doi. org/10.1111/rego.12041

de Zwart, F. 1994. The bureaucratic merry-go-round: manipulating the transfer of Indian civil servants. Amsterdam University Press, Amsterdam, The Netherlands. http://dx.doi.org/10.5117/9789053561324

Dilling, L., and M. C. Lemos. 2011. Creating usable science: opportunities and constraints for climate knowledge use and their implications for science policy. Global Environmental Change 21:680-689. http://dx.doi.org/10.1016/j.gloenvcha.2010.11.006

Edelenbos, J., A. van Buuren, and N. van Schie. 2011. Coproducing knowledge: joint knowledge production between experts, bureaucrats and stakeholders in Dutch water management projects. Environmental Science and Policy 14:675-684. http://dx.doi.org/10.1016/j.envsci.2011.04.004

Fazey, I., A. C. Evely, M. S. Reed, L. C. Stringer, J. Kruijsen, P. C. L. White, A. Newsham, L. Jin, M. Cortazzi, J. Phillipson, K. Blackstock, N. Entwistle, W. Sheate, F. Armstrong, C. Blackmore, J. Fazey, J. Ingram, J. Gregson, P. Lowe, S. Morton, and C. Trevitt. 2013. Knowledge exchange: a review and research agenda for environmental management. Environmental Conservation 40:19-36. http://dx.doi.org/10.1017/S037689291200029X

Ferraro, P. J., and S. K. Pattanayak. 2006. Money for nothing? A call for empirical evaluation of biodiversity conservation investments. PLoS Biology 4(4):e105. http://dx.doi.org/10.1371/ journal.pbio.0040105

Fleischman, F. D. 2014. Why do foresters plant trees? Testing theories of bureaucratic decision-making in Central India. World Development 62:62-74. http://dx.doi.org/10.1016/j.worlddev.2014.05.008

Fleischman, F. 2015. Understanding India's forest bureaucracy: a review. Regional Environmental Change 1-13. http://dx.doi. org/10.1007/s10113-015-0844-8

Gadgil, M., and F. Berkes. 1991. Traditional resource management systems. Resource Management and Optimization $8: 127-141$.

Gadgil, M., and R. Guha. 1992. This fissured land: an ecological history of India. Oxford University Press, New Delhi, India. http:// dx.doi.org/10.1093/acprof:oso/9780198077442.001.0001

Gadgil, M., and R. Guha. 1995. Ecology and equity. United Nations Research Institute for Social Development, New York, New York, USA.

George, A. L., and A. Bennett. 2005. Case studies and theory development in the social sciences. MIT Press, Cambridge, Massachusetts, USA.

Guston, D. H. 2001. Boundary organizations in environmental policy and science: an introduction. Science, Technology and Human Values 26:399-408. http://dx.doi.org/10.1177/016224390102600401

Hannam, K. 2000. Educating an environmental elite: the training of the Indian Forest Service. International Research in Geographical and Environmental Education 9:285-295. http://dx. doi.org/10.1080/10382040008667661 
Hirt, P. W. 1994. A conspiracy of optimism: management of the national forests since World War Two. University of Nebraska Press, Lincoln, Nebraska, USA.

Holling, C. S., and G. K. Meffe. 1996. Command and control and the pathology of natural resource management. Conservation Biology 10:328-337. http://dx.doi.org/10.1046/j.1523-1739.1996.10020328. $\underline{\mathrm{x}}$

Iyer, L., and A. Mani. 2012. Traveling agents: political change and bureaucratic turnover in India. Review of Economics and Statistics 94:723-739. http://dx.doi.org/10.1162/REST a 00183

Jantarasami, L. C., J. J. Lawler, and C. W. Thomas. 2010. Institutional barriers to climate change adaptation in U.S. national parks and forests. Ecology and Society 15(4):33. [online] URL: http://www.ecologyandsociety.org/vol15/iss4/art33/

Kaufman, H. 1960. The forest ranger: a study in administrative behavior. Resources for the Future, Washington, D.C., USA.

Koontz, T. M. 2007. Federal and state public forest administration in the new Millennium: revisiting Herbert Kaufman's The forest ranger. Public Administration Review 67:152-164. http://dx.doi. org/10.1111/j.1540-6210.2006.00704.x

Lewis, M. 2002. Scientists or spies? Ecology in a climate of Cold War suspicion. Economic and Political Weekly 37:2323-2332.

Lewis, M. 2004. Inventing global ecology: tracking the biodiversity ideal in India, 1947-1997. Ohio University Press, Athens, Ohio, USA.

Lewis, M. 2005. Indian science for Indian tigers?: conservation biology and the question of cultural values. Journal of the History of Biology 38:185-207. http://dx.doi.org/10.1007/s10739-004-1486-8

Lidskog, R. 2014. Representing and regulating nature: boundary organisations, portable representations, and the science-policy interface. Environmental Politics 23:670-687. http://dx.doi. org/10.1080/09644016.2013.898820

Ludwig, D. 2001. The era of management is over. Ecosystems 4:758-764. http://dx.doi.org/10.1007/s10021-001-0044-x

Madhusudan, M., K. Shanker, A. Kumar, C. Mishra, A. Sinha, R. Arthur, A. Datta, M. Rangarajan, R. Chellam, G. Shahabuddin, R. Sankaran, M. Singh, R. Uma, and P. D. Rajan. 2006. Science in the wilderness: the predicament of scientific research in India's wildlife reserves. Current Science 91:1015-1019.

McCubbins, M. D., R. G. Noll, and B. R. Weingast. 1987. Administrative procedures as instruments of political control. Journal of Law, Economics, and Organization 3:243-277.

McCubbins, M. D., R. G. Noll, and B. R. Weingast. 1989. Structure and process, politics and policy: administrative arrangements and the political control of agencies. Virginia Law Review 75:431-482. http://dx.doi.org/10.2307/1073179

McDermott, C., B. W. Cashore, and P. Kanowski. 2010. Global environmental forest policies: an international comparison. Earthscan, London, UK.

McGinley, K., R. Alvarado, F. Cubbage, D. Diaz, P. J. Donoso, L. A. G. Jacovine, F. L. de Silva, C. MacIntyre, and E. M. Zalazar.
2012. Regulating the sustainability of forest management in the Americas: cross-country comparisons of forest legislation. Forests 3:467-505. http://dx.doi.org/10.3390/f3030467

Miller, G. J. 1993. Managerial dilemmas: the political economy of hierarchy. Cambridge University Press, Cambridge, UK. http:// dx.doi.org/10.1017/cbo9781139173742

Ministry of Environment and Forests. 1988. National forest policy resolution, 1988. Ministry of Environment and Forests, Government of India, New Delhi, India. [online] URL: http:// www.moef.gov.in/sites/default/files/introduction-nfp.pdf

Nie, M. 2008. The underappreciated role of regulatory enforcement in natural resource conservation. Policy Sciences 41:139-164. http://dx.doi.org/10.1007/s11077-008-9060-4

Olson, M. 1965. The logic of collective action: public goods and the theory of groups. Harvard University Press, Cambridge, Massachusetts, USA.

Olsson, P., and C. Folke. 2001. Local ecological knowledge and institutional dynamics for ecosystem management: a study of Lake Racken Watershed, Sweden. Ecosystems 4:85-104. http://dx. doi.org/10.1007/s100210000061

Pullin, A. S., T. M. Knight, D. A. Stone, and K. Charman. 2004. Do conservation managers use scientific evidence to support their decision-making? Biological Conservation 119:245-252. http://dx. doi.org/10.1016/j.biocon.2003.11.007

Raymond, C. M., I. Fazey, M. S. Reed, L. C. Stringer, G. M. Robinson, and A. C. Evely. 2010. Integrating local and scientific knowledge for environmental management. Journal of Environmental Management 91:1766-1777. http://dx.doi.org/10.1016/ j.jenvman.2010.03.023

Robbins, P. 2000. The practical politics of knowing: state environmental knowledge and local political economy. Economic Geography 76:126-144. http://dx.doi.org/10.2307/144550

Roux, D. J., K. H. Rogers, H. C. Biggs, P. J. Ashton, and A. Sergeant. 2006. Bridging the science-management divide: moving from unidirectional knowledge transfer to knowledge interfacing and sharing. Ecology and Society 11(1):4. [online] URL: $\underline{\text { http:// }}$ www.ecologyandsociety.org/vol11/iss1/art4/

Rowley, W. D. 1985. U.S. Forest Service grazing and rangelands a history. Texas A and M University Press, College Station, Texas, USA.

Saberwal, V. K. 1999. Pastoral politics: shepherds, bureaucrats, and conservation in the Western Himalaya. Oxford University Press, Delhi, India.

Sayre, N. F. 2010. Climax and "original capacity": the science and aesthetics of ecological restoration in the Southwestern USA. Ecological Restoration 28:23-31. http://dx.doi.org/10.3368/ er.28.1.23

Scott, J. C. 1998. Seeing Like a state. Yale University Press, New Haven, Connecticut, USA.

Singh, N. J., and S. Bagchi. 2013. Applied ecology in India: scope of science and policy to meet contemporary environmental and socio-ecological challenges. Journal of Applied Ecology 50:4-14. http://dx.doi.org/10.1111/1365-2664.12020 
Stankey, G. H., B. T. Bormann, C. Ryan, B. Shindler, V. Sturtevant, R. N. Clark, and C. Philpot. 2003. Adaptive management and the northwest forest plan: rhetoric and reality. Journal of Forestry 101:40-46. [online] URL: http:// andrewsforest.oregonstate.edu/pubs/pdf/pub3236.pdf

Stankey, G. H., R. N. Clark, and B. T. Bormann. 2005. Adaptive management of natural resources: theory, concepts, and management institutions. General Technical Report PNWGTR-654. U.S. Department of Agriculture, Forest Service, Pacific Northwest Research Station, Portland, Oregon, USA. [online] URL: http://www.fs.fed.us/pnw/pubs/pnw gtr654.pdf

Stebbing, E. P. 1922. The forests of India. Vols. i-iii. Dodley Head, London, UK.

Sunderlin, W. D., J. Hatcher, and M. Liddle. 2008. From exclusion to ownership? Challenges and opportunities in advancing forest tenure reform. Rights and Resources Group, Washington, D.C., USA. [online] URL: http://www.rightsandresources.org/documents/ files/doc 736.pdf

Teodoro, M. P. 2011. Bureaucratic ambition: careers, motives, and the innovative administrator. Johns Hopkins University Press, Baltimore, Maryland, USA.

Tipple, T. J., and J. D. Wellman. 1991. Herbert Kaufman's forest ranger thirty years later: from simplicity and homogeneity to complexity and diversity. Public Administration Review 51:421-428. http://dx.doi.org/10.2307/976411

Weiss, C. H. 1988. Evaluation for decisions: is anybody there? Does anybody care? Evaluation Practice 9:5-19. http://dx.doi. org/10.1016/S0886-1633(88)80017-5

Wood, B. D., and R. W. Waterman. 1991. The dynamics of political control of the bureaucracy. American Political Science Review 85:801-828. http://dx.doi.org/10.2307/1963851

Yackee, S. W. 2006. Sweet-talking the fourth branch: the influence of interest group comments on federal agency rulemaking. Journal of Public Administration Research and Theory. 16:103-124. http://dx.doi.org/10.1093/jopart/mui042 